\title{
The Current Situation, Problems and Countermeasures of E-commerce Development in Gansu Province
}

\author{
Haiying $\mathrm{Ma}^{1, \mathrm{a}^{*}}$, and Liqiong Yang ${ }^{2, \mathrm{~b}}$ \\ ${ }^{1,2}$ Provincial Key Laboratory of E-commerce of Ethnic Information \& \\ School of Economics, Northwest Minzu University, Lanzhou (730124), P.R.China \\ axmahaiying8888@163.com, b1123002683@qq.com
}

\begin{abstract}
Keywords: Internet plus; Electronic commerce; Countermeasures; Gansu
\end{abstract}
\begin{abstract}
As an important component of China's strategic emerging industries, e-commerce has sprung up in the new economic norm. In this paper, on the basis of in-depth research, systematically analyzes the existing problems in the development of electronic commerce in Gansu, and puts forward some countermeasures and suggestions to promote the development of electronic commerce in Gansu Province, in order to provide a reference for the rapid development of e-commerce in our province.
\end{abstract}

\section{Introduction}

In recent years, e-commerce, as a new mode of commercial economy, has penetrated into every field of national economy and social life. Located in the heartland of Northwest China, Gansu province is the golden section of the Silk Road Economic Belt. It is an important gateway for our country to open to the west. E-commerce as a new business model, first appeared in the eastern part of China's developed markets, and then developed rapidly to the central and Western provinces. At present, the electronic commerce in the form of "Internet plus" impact on China's economic and social development has become increasingly significant, promoting China's economic and social development of the new power can not be ignored. The development degree of the market economy in Gansu has been lagging behind the eastern provinces, and the speed and level of the development of e-commerce have also been greatly restricted. But with the national The Belt and Road and Internet plus strategic launch and in-depth implementation of the Gansu area, transportation, communications and other infrastructure have rapidly improved, from 2010s onwards, the electronic commerce in Gansu also ushered in the golden period of development. Gansu province is located in Northwest China Center, both natural conditions and transportation, communications and other infrastructure, whether it is a market economy or the market awareness of the level of economic development, whether it is GDP or per capita income per capita, in 12 western provinces are ranked in the lower level, the development of electronic commerce is extremely difficult. The development of electronic commerce is the inevitable choice of economic development in the information era, although electronic commerce in Gansu province started late, small scale, but because of the Gansu provincial government departments at all levels attach great importance to and strong push, the 14 city of the province of the development of electronic commerce are showing a good momentum of rapid development, at the same time, there are many worthy theory community and government departments in-depth discussion.

\section{The Current Situation of E-commerce Development in Gansu Province}

Electricity Providers Increasingly Popular Applications. By the end of 2014, Gansu province has more than 30 thousand registered online shop at the end of 2013, an increase of $8.6 \%$, of which nearly $80 \%$ shops in the sale of agricultural products, agricultural products e-commerce transactions accounted for the province's total e-commerce transactions $65 \%$. Enterprise shop more than 3500, compared to the end of the year growth of $9.4 \%$. At present, the application of electronic commerce in our province agricultural products, food, medicine, art, electrical and mechanical, petrochemical, building materials and other industries continue to expand, and the real level of economic integration continues to improve, 
especially agricultural products e-commerce application gradually mature, the emergence of the enterprise + base + shop + base or Association (cooperative) and the new mode of rural e-commerce shop.

The Government Paying Great Importance to Unprecedented Improvement. In recent years, the Gansu provincial Party committee and the provincial government have attached great importance to the development of e-commerce. First, the establishment of the leading group of e-commerce industry development in Gansu Province, vice governor Li Rongcan as head of the group, 28 related departments as member units. Two is the introduction of the Gansu Provincial People's government views on accelerating the development of e-commerce industry, made 22 specific measures to promote the province's e-commerce development focus on four aspects, proposed to build the Gansu West open online Silk Road, pointed out the direction for the development of electronic commerce to provide the policy support. Three is the preparation of the Gansu e-commerce development plan.

In 1997, we set up the guiding ideology of the development of e-commerce in Gansu Province, formulated the goal of development, defined the tasks of the work and strengthened the support and support. Four is to successfully carry out the province's e-commerce work site meeting, greatly enhanced the profound understanding of e-commerce at all levels of government, boosted the confidence of the development of the electricity supplier enterprises. Five is the successful completion of Taobao network characteristic China-Gansu Pavilion, to promote the province's e-commerce development, gradually step onto the fast lane.

Innovative Initiatives Significant Results. First of all, actively explore innovative "blue fair" will do model, held palm blue Association. In 2014, the two phase of the fair will set up two-dimensional code scanning area, through the mobile phone scanning two-dimensional code to achieve shopping. Secondly, the cross-border electricity suppliers to build a platform to promote the opening to the west, the development and construction of the long Huitong platform, our province enterprises and commodity information formed in Britain, Russia, Arabia, Japan, Korea and other multi language version, to achieve a set of trade information and application services, online trading is one of the first provincial Gansu cross-border e-commerce series platform. Thirdly, in cooperation with the Hong Kong Trade Development Council, with the help of the Hong Kong Trade Development Council (TDC) platform for the construction of an overseas Gansu Pavilion, China has fully displayed the advantages of its resources and expanded and expanded its sales scale and sales channels. Finally, in striving for and grasp the national e-commerce model city, demonstration bases, demonstration enterprise construction at the same time, the innovation and development of our provincial e-commerce demonstration system, and in the province opened the provincial e-commerce demonstration counties, base and enterprise selection.

E-supplier Awareness Improved. In accordance with the Gansu e-commerce personnel training program to take effective measures to comprehensively promote e-commerce business training. First, the introduction of Taobao University, settled in Gansu, e-commerce training courses applied talents. Two is the use of rich people, Xing Long series of lectures, invited well-known national e-commerce experts to do seminars on e-commerce seminars. The three is the joint Alibaba Gansu service center to develop electronic commerce of cities and counties in the province tour Organization (B2B) is widely used in e-commerce business training, explanation and guidance on cadres, enterprises and the masses, popularize and deepen the knowledge of electronic commerce, to provide talent support and intellectual support for the development of rural electricity supplier.

The Geographical Advantages Becoming Apparent. Eurasia throat position of Gansu, is the Eurasian continental bridge connecting channels and communication strategies for the southwest and northwest of the transport hub, is the northwest and the important ecological security barrier, an important national base of new energy, non-ferrous metallurgy and new materials base and characteristics of agricultural production and processing base, the country's only circular economy demonstration province. Area of Chinese civilization inheritance and innovation, promote the common solidarity and common prosperity and development of the national demonstration zone, is an important gateway to the west of China, has an important position in the overall situation of national development and stability in the. 


\section{The Main Problems in the Development of E-commerce in Gansu}

Small Number of Local E-supplier Enterprises with Small Scale. At present, the province's e-commerce platform less, access, volume of transactions, visibility and other well-known platforms than the gap between the larger. E-commerce practitioners in the majority of individual or individual businesses, small-scale, scattered distribution.

E-commerce Professionals Shortage. The lack of e-commerce professionals and rural area, the lack of independent operation and management of online practical talents, enterprises lack of information technology, network operations, activities such as planning talents, lack of talent has become a major bottleneck in the development of electronic commerce in our province.

Enterprise Financing Difficulties. Due to the small size, weak strength and lack of effective collateral, the electronic commerce enterprises have many problems, such as high financing frequency and quick cash flow.

Poor Standardization of Agricultural Products and Integration of Resources. The characteristics of agricultural products in the production process there is no standard to follow or not the standard, some products have made green and organic and pollution-free and other professional qualifications, and the Gansu area narrow, scattered resources, competitive enterprises sell products homogenization, affect the sales price.

Development of E-commerce Infrastructure Needs to be further Improved. The broadband network coverage is still low especially in some remote rural broadband network, related service ability, payment, financing and other e-commerce support system needs to be further improved; logistics distribution network is not perfect, the coverage is small, the information is lagging behind, logistics enterprise scale is small, the high cost of express delivery.

Geographical Environment Factors. Gansu topography is complex, wasteland of Western and eastern areas of Gobi mountain deep ditch, uneven distribution of population, transportation cost and network infrastructure construction, high business difficulties, development is seriously lagging behind, the development of the electricity supplier, compared with the eastern developed regions, increasing the number of infrastructure construction cost.

\section{Promotion of the Development of E-commerce in Gansu}

Accelerating the Construction of E-commerce Infrastructure. At present, matched with the electronic commerce logistics resource rich, a huge network of express delivery service, but higher fees, standards, directly affect the electricity supplier in our province electricity supplier and shop operators operating costs and benefits, especially the rural distribution network is not fully in place. It is suggested that the overall planning of the province should be promoted and the infrastructure construction of e-commerce should be accelerated. First, vigorously develop the modern logistics service system. In promoting the construction of rural informatization and the construction of e-commerce demonstration cities, we should give priority to poor areas, help backward areas eliminate the "digital gap", and develop rural logistics in many ways. Encourage enterprises to set up logistics service outlets in the country to provide services, the Department of Commerce farm shop goods distribution motorists to help rural shop to solve logistics problems. Two is to accelerate the construction of Internet infrastructure. We should coordinate telecom operators' active investment and adopt wired and wireless complementary measures to speed up network construction. County governments can adopt financial subsidies to cooperate with communication enterprises, and provide priority to broadband networks for villages that have set up shop demands. As soon as possible to implement the city's large public places hot information wireless coverage project, supervision and implementation of the contract involved in construction projects and content, improve the quality of network services. Actively promote the telecommunications network, radio and television networks and Internet triple play, do a good job in rural online project, to enhance the level of informationization in rural areas, as soon as possible to complete the cable into the village, giving priority to cooperatives and rural electricity supplier service point network coverage problem. 
Promoting the Training and Introduction of E-supplier Talents. The special agricultural products in our province are mainly distributed in rural areas. In order to realize large-scale online sales, we must rely on village cadres, college students village officials, farmers and young entrepreneurs returning home. Therefore, the development of e-commerce talents is the key. Therefore, we should conscientiously implement the Gansu province e-commerce talent training program, please come in and go out" the method of combining the domestic electricity supplier experts, Alibaba invited lecturer to Gan workshops, selected key personnel to developed areas of learning, to carry out the business elite, Taobao, poverty alleviation two epigenetic and multi level training and speed up the formation of culture mechanism of e-commerce talent combination. We will implement preferential policies for the introduction of talents, introduce e-commerce professionals through various channels, improve the training and training mechanism for e-commerce talents, and prevent brain drain. Use various forces to explore the establishment of e-commerce online schools, online training, the establishment of e-commerce professional certification system. Establishing a database of reserved talents. Give full play to the advantages of provincial colleges and universities in infrastructure and teachers, and provide strong support for the professional talents training of Gansu electricity supplier.

Efforts to Cultivate E-supplier Leading Enterprises. From the experience of developed areas, e-commerce leading enterprises in attracting high-end enterprise platform settled, improve the local e-commerce infrastructure, and promote the development of local e-commerce demonstration effect is very significant. To this end, Gansu should first cultivate the electricity supplier leading enterprises as the focus of work, in policy support, planning and development, financing services, environmental construction and other aspects of key tilt. In various industries and formats to cultivate a number of e-commerce leading enterprises, better play exemplary role. The two is a great loss, in support of the local leading enterprises to carry out network marketing, give full play to the organization to promote the role of electronic commerce services consulting and industry associations, and constantly improve the main business e-commerce scale, cultivate leading enterprise e-commerce carrier type. Three is to continue to strive for national support, and do a good job of e-commerce demonstration cities, demonstration bases, public service platform demonstration sites, integration

Improvement of the Quality Supervision and Traceability System. In order to ensure the sustained and stable development of e-commerce, it is essential to establish and improve the quality supervision and traceability system. First of all we have to grasp the source of supervision, strict monitoring of origin: one is by the food and drug administration, Department of agriculture and animal husbandry, the Quality Supervision Bureau and other departments to strengthen supervision of e-commerce of agricultural products, native products of tracking monitoring, to prevent the safety on the tongue hidden. Two is to establish and improve the quality of network marketing quality traceability system. The global identification system in e-commerce merchandise management, shop management, logistics management, information sharing and exchange, analysis of information equivalence to meet consumer needs to obtain precise, enhance the transparency and credibility of products. With the advanced information technology, the whole process of informatization management of agricultural products is carried out to satisfy the consumers' right to know and supervise. Protect consumers from the harm of fake and shoddy products, and promote fair trade in e-commerce.

Building Characteristic Advantage Brand. First, we must implement standardized production and management. From planting (fission) technology to the purchase and sale of storage and transportation, deep and fine processing, cultivating a number of high yield, good quality, wide influence the characteristics of agricultural products, improve agricultural product quality and grade, expand product market share, improve the market competitiveness of products. The two is to speed up the three one, pollution-free agricultural products, green food, organic food and agricultural products

\section{Conclusions and Suggestions}

Through the analytic hierarchy process can be seen, the transaction subject to the e-commerce of agricultural products, agricultural products brand cognitive degree, transactions subject to the level of information, e-commerce transaction security, transaction platform visibility, agricultural products 
standardization and other factors on the development of Gansu Province agricultural product electronic commerce has remarkable effect. According to the factors influencing the development of e-commerce of agricultural products in Gansu Province, we hereby put forward the opinions: (1) to strengthen the training and education of Gansu province in the main agricultural enterprises, farmers and other agricultural products e-commerce. (2) establishing standardized agricultural product quality testing system and sorting and packaging system of agricultural products, so as to enhance the brand awareness of agricultural products in Gansu. (3) formulate relevant e-commerce transaction security regulations, and improve the safety consciousness of the participants.

\section{Acknowledgements}

This work was supported by the Key Laboratory of E-commerce of Ethnic information in Gansu Provincial and Comprehensive experimental teaching center in Economics(Grant No. 2016XJSYJXSF2X-01-10019109) and by Special Funds for Undergraduate Teaching Reform by Central University of Northwest Minzu University (Grant No:10019153 ).

\section{References}

[1] Ye Mei, Current situation and problems of e-commerce in China. Commercial Economy, 7(2010)35-37.

[2] Zhang Hui, Status of China's e-commerce development. China Economic and Trade, 2012.

[3] Huang Huang, Government promotion of e-commerce. Party School of CPC Central Committee, 2006.

[4] Liao Yunxia, Tao Zhihui, Electronic commerce. Beijing: Beijing University of Posts and Telecommunications press, 2002.

[5] Liu Shizhong, Research on the training methods of outsourcing of e-commerce talents. Education and teaching forum, 9(2015) 34-35.

He Fei Yingyan, Study on the logistics system of agricultural products under electronic commerce. Market Theory, 2009, (9). (6)

[7] Liu Yuyan, The development of e-commerce under the background of new countryside. Science Herald, 2016.

[8] Zheng Yaqin, Zheng Wensheng, Discussion on the construction of evaluation index system of rural e-commerce. Technology and economics, 3 (2007) 63-67.

[9] Yang Xiaoling, Analysis of the development of e-commerce in minority areas. Chinese e-commerce, 4 (2011) 28-29. 